\title{
Componentes teóricos para la comprensión de la pedagogía intercultural como práctica docente
}

\author{
Cindy Artavia \\ Docente de la División de Educación para el Trabajo de la Universidad Nacional \\ Heredia, Costa Rica \\ Lode Cascante \\ Docente de la División de Educología de la Universidad Nacional \\ Heredia, Costa Rica
}

Recibido $1^{\circ}$ de noviembre de $2007 \bullet$ Aprobado 15 de marzo de 2008

\begin{abstract}
Resumen. En la actualidad, un tema que aparece en el ámbito educativo como respuesta a las demandas de una sociedad cada vez más diversa y que exige procesos de inclusión, es, sin duda, el concepto de interculturalidad. Existe una serie de acercamientos conceptuales que distan mucho de crear una pedagogía de la interculturalidad, sobre todo, cuando se valora la interculturalidad como una filosofía, que requiere de un nuevo docente capaz de reciclarse, y que atienda al cambio paradigmático que demanda la interculturalidad.

Este escrito presenta un acercamiento a los componentes teóricos para la comprensión de la pedagogía intercultural como una práctica educativa. Se inicia con una breve presentación de la educación en nuestro tiempo, la interpretación de los derechos humanos como parte fundamental de la diversidad humana, la interculturalidad desde la escuela con los enfoques y los modelos explicativos de esta pedagogía, para, finalmente, abordar de forma breve algunas competencias interculturales de los docentes ante la diversidad.
\end{abstract}

Palabras clave. Interculturalidad, derechos humanos, xenofobia, pedagogía intercultural, competencias interculturales.

\footnotetext{
Máster en Pedagogía y Licenciada en Orientación Educativa de la UNA. Es orientadora en el Liceo Otilio Ulate Blanco de San Isidro de Alajuela y académica de la División de Educación para el Trabajo. Correo electrónico: cindyartavia@yahoo.com

2 Máster en Pedagogía y Licenciada en La Enseñanza de los Estudios Sociales de la UNA. Académica de la División de Educología y Coordinadora Académica del Colegio Marista de Alajuela. Correo electrónico: lodelena@yahoo.com
} 
Abstract. Nowadays, a topic that arises in the educational domain as an answer to the demands of an increasingly diverse society which also demands processes of inclusion is, without a doubt, the concept of interculturalism. There are several conceptual approaches that are far from creating a pedagogy of interculturalism, specially when interculturalism is valued as a philosophy, which requires the development of a new teacher who is not only capable of recycling him/herself but who is also aware of the paradigmatic changes that interculturalism demands.

The article presents an approach to the theoretical components for the understanding of intercultural pedagogy as an educational practice. It begins with a brief presentation of the current educational system, followed by the interpretation of human rights as a fundamental issue of human diversity, and certain approaches and clarification models for interculturalism in elementary school. Finally, the article briefly discusses some of teacher's intercultural competencies in the face of such diversity.

Key words. Interculturalism, human rights, xenophobia, multicultural education, intercultural pedagogy, intercultural challenges.

La atención en la escuela ya no se centra en las deficiencias de las personas, sino en buscar qué recursos provee la escuela como respuesta social y educativa."

Pilar Arnaiz

\section{LA EDUCACIÓN EN NUESTRO TIEMPO}

La educación ha sido, en el transcurso de este siglo, -y, posiblemente lo seguirá siendo en el futuro- uno de los instrumentos más importantes con los que han contado las sociedades modernas para luchar contra las desigualdades sociales, para hacer frente a los fenómenos y a los procesos de segregación y exclusión social, para establecer, ampliar y profundizar los valores cívicos y democráticos, para impulsar el desarrollo económico y cultural, y para promover el desarrollo personal y el mejoramiento de la calidad de vida de todos sus miembros.

Sin embargo, la manera como están organizados, actualmente, los sistemas educativos e, incluso, la concepción misma de la educación que sustenta esta organización y sus soluciones, tendrá que experimentar cambios profundos para hacer frente a los desafíos del nuevo escenario económico, social, político y cultural que ha empezado a perfilarse durante el transcurso de las últimas décadas y que se recorta, ya con claridad, en el horizonte.

Educación es un concepto amplio que, en su sentido original, designa un conjunto de actividades y prácticas sociales, mediante las cuales los grupos humanos promueven el desarrollo personal y la socialización de sus miembros, y garantizan el funcionamiento de uno de los mecanismos esenciales de la evolución de la especie: la herencia cultural.

Los grupos humanos han utilizado, siempre y simultáneamente, diversos tipos de prácticas y actividades sociales, con el fin de facilitar a las nuevas generaciones el acceso a las formas y a los saberes culturales -conocimientos y creencias sobre el mundo, el lenguaje y los instrumentos para conocer la realidad y actuar sobre ella, las tecnologías y las técnicas, las tradiciones, los sistemas de valores, entre otros- considerados fundamentales para la supervivencia colectiva y cuya apropiación individual se juzga necesaria, en consecuencia, para llegar a formar parte de ellos como miembros de pleno derecho. En todo tipo de sociedad, la responsabilidad en la organización y la conducción de estas prácticas y actividades sociales ha estado a cargo de diferentes actores y, a menudo, también, 
de diferentes instancias, las cuales, desde su rol específico y su ubicación en la organización social, cultural y económica establecida, contribuyen, conjuntamente, al desarrollo personal y a la socialización de las nuevas generaciones.

Ante los retos de entrar a la denominada sociedad del conocimiento, ya no se puede seguir con los modelos del pasado en materia de organización económica ni educativa; se deben visualizar nuevas tendencias educativas que favorezcan el desarrollo de una serie de competencias y destrezas, con el fin de facilitar el aprender a ser y el aprender a vivir juntos.

Si la educación tiene un sentido, camina necesariamente en una dirección y cumple una serie de funciones, es prudente aclarar ese sentido para realizar una práctica reflexiva. Por tanto, se considera que existe una serie de derechos universales que guían y dan directrices a la educación, en general, entre los que se destacan los derechos humanos.

Cuando se habla de derechos humanos, en relación con la educación, suelen abordarse, por lo general, algunos enfoques, como el derecho a la educación, al abordaje de temas relacionados con los derechos humanos en los centros educativos y el respeto de éstos en las prácticas educativas, entre otras, como lo expresa Gimeno Sacristán (2005, p. 124) "[...] una perspectiva de educación desarrollada, según los derechos humanos, tanto el derecho a la educación como otros con los que éste se relaciona".

\section{DERECHOS HUMANOS}

En los albores de un nuevo siglo, toda sociedad debe plantearse algunas preguntas. ¿Es ésta suficientemente integradora? ¿Está excluida en ella la discriminación? ¿Son sus normas de comportamiento conformes con los principios consagrados en la Declaración Universal de los Derechos Humanos?

Estas interrogantes se deben plantear, pues aún no ha desaparecido el racismo, la discriminación racial, la xenofobia y otras formas de intolerancia. Es importante reconocer que aún existen en el nuevo siglo, y su persistencia está enraizada en diferentes temores, tales como: temor a lo diferente, temor del uno al otro, temor a la pérdida de la seguridad personal. Al mismo tiempo, hay que reconocer que el temor humano es, en sí mismo, imposible de erradicar, pero existe un convencimiento de que sus consecuencias sí pueden ser erradicadas.

Todos los seres humanos constituyen una sola familia. Esta verdad ha quedado, evidentemente, establecida tras la primera descripción completa del genoma humano, un logro extraordinario que no sólo reafirma nuestra humanidad común; sino que promete transformaciones en el pensamiento y en las prácticas científicas, así como en las aspiraciones que para sí puede abrigar la especie humana. Esto constituye un aliciente hacia el pleno ejercicio del espíritu humano, hacia un nuevo despertar de todas las capacidades inventivas creativas y morales, realzando la participación equitativa de hombres y mujeres. Sólo entonces, el siglo veintiuno podría ser una era de logros genuinos y de paz.

Desde que, en 1948, se aprobó la Declaración Universal de los Derechos Humanos, la comunidad internacional ha avanzado, considerablemente, en la lucha contra el racismo, la discriminación racial, la xenofobia y las formas conexas de intolerancia. Se han promulgado leyes de aplicación nacional e internacional, y se han aprobado numerosos instrumentos internacionales de derechos humanos, en particular: un tratado de prohibición de la discriminación racial. Pese a que se han logrado éxitos espectaculares, como la eliminación del Apartheid en Sudáfrica, el sueño de que el mundo se vea libre del odio y los prejuicios raciales sólo se ha hecho realidad a medias. 
Mientras que la tecnología acerca a los pueblos del mundo, la discriminación racial, la xenofobia y otras formas de intolerancia siguen asolando la sociedad. Cabe destacar que hasta, lastimosamente, se ha acuñado un nuevo término, el de depuración étnica, para referirse al caso de los conflictos en los Balcanes, a mediados de 1990, y describir un horror antiguo, en tanto la ideología de la superioridad racial se ha extendido a la Internet. Incluso la mundialización, con sus ventajas potenciales, lleva aparejados algunos riesgos que pueden conducir a la exclusión y a un aumento de la desigualdad, con mucha frecuencia, por consideraciones raciales y étnicas.

Hoy vivimos una época caracterizada por la dominación total de los derechos humanos y su avasalladora ideología. Esta situación ha provocado la reacción de pensadores y analistas que han intentado volver a situarlos en su espacio específico, es decir, derechos humanos como condiciones previas e imperativas de toda vida democrática, como propulsores de su ejercicio, pero no como sus únicos y principales contenidos. Este imperialismo ideológico pervierte el sentido original de los derechos humanos y la radicalidad de su apuesta transformadora.

En tiempos actuales, los discursos de justificación a la discriminación han cambiado, ya no consisten en argumentos a favor de la pureza de la "raza aria" o de la "civilización blanca", sino que han surgido nuevos discursos que justifican y operan dando cobertura a las continuas acciones que conducen a ciertas poblaciones hacia un nivel de inferioridad e indignidad humillante e intolerable. La ciencia ha dejado de expresar su voz en uno u otro sentido, ya sea a favor o en contra de las diferencias. De ella, se han servido la política, la economía para justificar las invasiones y el colonialismo, entre otros. Pero, afortunadamente, no toda la ciencia y los científicos trabajan con los mismos supuestos teóricos o las mismas estrategias de búsqueda del conocimiento.

Pero, a pesar de ello, Martínez y Sáez (1998), consideran que:

[...] el racismo ha falsificado groseramente los datos aportados por la biología sobre el hombre. No ha tenido ningún pudor en distribuir, con tonos jerárquicos, a los grupos humanos según sus "inconmovibles e innatas propiedades psicológicas y culturales“ o ha intentado defender como fundamentales y primarias, en sus clasificaciones racistas, las diferencias morfológicas y fisiológicas entre las personas de los distintos pueblos: ya sea argumentando que tales diferencias explican una distinta estructuración del cerebro ya sea para, en consecuencia, justificar la incompatibilidad de las culturas. (p. 20)

Las doctrinas racistas, las teorías raciales pseudocientíficas que han ido mostrando su inconsistencia científica, siguen siendo un instrumento poderoso para quienes no desean asumir la comunidad de origen de todos los pueblos que componen la humanidad. Los mismos autores opinan que:

Las ideas racistas están impidiendo, de algún modo, el desarrollo de la libre comunicación, el contacto entre los pueblos, el intercambio de valores entre culturas así como la cooperación auténtica entre colectivos y pueblos. El fundamentalismo que acompaña los procesos de racionalización actuales y el oscurantismo de los grupos que los justifican están obstaculizando el progreso histórico de todas las culturas y la emergencia de la civilización humana en el mestizaje. (p. 21).

En el inicio del siglo XXI, los profundos cambios socioeconómicos y las múltiples transformaciones tecnológicas, proyectan una realidad mundial y un período histórico cada vez más diversificado, fragmentado y globalizado. La lógica del desarrollo que orientó la cultura de la 
modernidad, sustentado durante siglos en modelos de conocimiento, de organización social y de política económica, ya no logra responder, satisfactoriamente, a las inquietudes, necesidades básicas y a demandas de la especie humana, las antiguas utopías de fundamentación y de legitimación se desmoronan, se transforman en incapaces de ofrecer directrices y patrones normativos seguros y, abren una brecha para redefinir los marcos epistemológicos y metodológicos que permiten viabilizar una nueva visión integral del ser humano, así como la estructuración de un nuevo orden mundial.

Las alternativas para la erradicación de la pobreza y para el mejoramiento de las condiciones socioeconómicas de la vida estimulan para definir nuevas fórmulas de reglamentación y nuevas prácticas políticas. Se destaca, así, el delineamiento necesario de otra forma de concebir la relación entre derecho y sociedad. La inscripción del emergente ya no privilegiará, con exclusividad, al estado o al mercado, sino al ser humano como sujeto central del desarrollo y como titular de los derechos humanos esenciales. En su potencialidad, el derecho al desarrollo trae al escenario institucional nuevos valores y nuevas formas de interrelaciones, que instauran una nueva dinámica entre el derecho y el desarrollo humano.

Por cierto, una correcta discusión paradigmática en el nuevo siglo, incluyendo derecho y desarrollo, por un lado, no puede prescindir de señalar las insuficiencias del sistema jurídico internacional identificado con el Estado-Nación, para captar el universo de la globalización y de las interdependencias complejas; por otro lado, debe expresar, más que nunca, formas alternativas de desarrollo que consideren la construcción específica de derechos económicos, sociales y culturales, pautados en valores e implementados en prácticas auténticas de una política dirigida hacia los derechos humanos.

Es necesario, hoy más que nunca, priorizar la recuperación integral del ser humano y redimensionar nuevas formas de participación comunitaria, para contraponerse a la crisis y a las nuevas formas de colonización presentadas por la sociedad globalizada en este recién iniciado milenio. Procesos de vida y de desarrollo material, afectados por contradicciones y perplejidades advenidas de la mundialización del modo de producir, vivir y dominar, expresan complejidades y exclusiones futuras. Eso ocurre porque el sistema de producción y de consumo se transnacionaliza, el EstadoNación tradicional se presenta debilitado; pierde, frente a inmensos conglomerados privados, gran parte de la iniciativa estratégica y tiene redefinidas sus funciones.

Repensar un nuevo modo de vida, expresión del ser humano como sujeto fundamental del desarrollo y partícipe de un orden mundial, implica tener conciencia y luchar contra imposiciones patronizadas que caracterizan la sociedad internacional estremecida con la debilitación de los estados nacionales, con la supremacía salvaje del mercado y con la hegemonía política del Neoliberalismo. En ese sentido, cabe aquí introducir un breve recorte del escenario cultural marcado por fenómenos como la globalización y el Neoliberalismo.

Delante del declive de las prácticas tradicionales en la gestión de políticas económicas, de la poca eficacia en responder a la pluralidad de las demandas y los conflictos, del creciente aumento de bolsones de miseria y de las nuevas relaciones colonizadoras de países ricos con naciones en desarrollo, se abre la discusión para la consciente búsqueda de alternativas capaces de desencadenar directrices, prácticas y reglamentaciones dirigidas hacia el desarrollo reordenador de una vida humana integral con dignidad.

Aún sin entrar en discusiones sobre la naturaleza, los fundamentos y la evolución histórica, no se podría dejar de mencionar, brevemente, que la doctrina de los derechos humanos ha respondido a los valores, exigencias y necesidades de distintos momentos históricos en la trayectoria de la sociedad moderna occidental. Así, hemos de reconocer ciertos matices procesales específicos de la concepción liberal-burguesa de los derechos humanos, de los siglos XVIII y XIX, y de aquella propia de fines del siglo XX, en un escenario de deconstrucción globalizante neoliberal. 
$\mathrm{Si}$, por un lado fue, ideológicamente, relevante la bandera de los derechos humanos como atributo de la lucha contra las formas arbitrarias de poder, y en defensa de la garantía de las libertades individuales, por otro lado, además de su idealización, asumir contornos formales y abstractos, su fuente de legitimación se reduce al poder oficial estatal. Se parte, de esa forma, de un formalismo monista en que toda producción jurídica moderna está confinada al poder del Estado.

Para enfrentar el momento histórico asumido por la apropiación del capital y por el orden internacional marcado por la globalización neoliberal, se percibe una nueva fase histórica y una nueva perspectiva teórica y política, en lo que se refiere a los derechos humanos. Se trata de cuestionar la naturaleza individualista, esencialista, estatista y formalista de los derechos, se debe partir de una redefinición de los derechos humanos, entendidos como procesos sociales, económicos, políticos y culturales que, por un lado, configuren, materialmente, ese acto ético y político maduro y radical de creación de un nuevo orden; y, por otro lado, la matriz para la constitución de nuevas prácticas sociales, de nuevas subjetividades antagonistas, diversas dentro de ese orden global vigente.

Es esencial, por tanto, el proceso de redefinir y consolidar la afirmación de derechos humanos en una perspectiva integral, local e internacional; pasar a incorporar nuevos derechos, con énfasis en los derechos económicos, sociales y culturales. Es fundamental, para la mejor comprensión de los derechos económicos, sociales y culturales, que se proponga un derecho al desarrollo, pues tal intento contempla no sólo el derecho a la inclusión de nuevos actores sociales internacionales, sino que también expresa el empeño de los países en vías de desarrollo a elaborar una identidad cultural colectiva.

Naturalmente, el derecho al desarrollo, como derecho humano individual e interdependiente, no sólo es producto de un nuevo orden mundial, resultante de cambios a escala planetaria, sino que, sobre todo, se vincula, de forma diferente, con la propia humanidad, o sea, pasa a ser un derecho en cuanto sujeto de obligaciones para con la comunidad mundial (Ianni, 1995). Es en tal escenario que se dibuja el esfuerzo por definir y consolidar un nuevo derecho humano al desarrollo como manifestación de un cuadro de mundialización, marcado por relaciones fundadas en la ética, en la equidad y en la solidaridad.

Lo que debe quedar claro es que la búsqueda de alternativas económicas, sociales y políticas sólo refuerza la obligatoriedad de los derechos humanos al desarrollo como proceso de lucha, direccionado contra un orden internacional antidemocrático, excluyente y colonizador. Frente a tales desafíos, cabe señalar, que apostando a la implementación de los derechos humanos como la más correcta plataforma emancipatoria de nuestro tiempo, hoy, más que nunca, la humanidad ha de inventarse un nuevo orden, más democrático e igualitario, capaz de valorizar la dignidad humana.

Los derechos humanos, partiendo desde su historia, evidencian una larga marcha, con avances y con retrocesos, difícilmente disociable del periplo ideológico que la ha acompañado paso a paso, y que ha perturbado su mensaje y enmarañado su desarrollo y cumplimiento. Cada autor pone en evidencia la necesidad de pensar y aplicar unos derechos humanos basados en valores no excluyentes, que permitan a la humanidad encaminarse hacia el progreso. Y sólo unos derechos humanos, planteados desde la perspectiva de la diversidad cultural, nos conducen a él.

Debe reconocerse, que pese a las muchas dificultades y obstáculos que se han presentado y los contextos, muchas veces, adversos, la educación en derechos humanos ha ido ganando terreno. Han sido incluidos, legalmente, dentro del currículum de casi todos los países. Además, con carácter transversal, los derechos humanos se han incorporado a la educación formal, junto con otros temas como el medio ambiente, la multiculturalidad, la interculturalidad, la orientación sexual, la salud, la educación para el consumo, y otros, en la perspectiva de la formación ciudadana, la formación para la vida y la formación para la vida democrática. 
De esta manera, se ha vinculado a la educación en derechos humanos con una serie de valores como el respeto a la vida, la libertad, la justicia, la solidaridad, la honestidad, la convivencia pacífica, la responsabilidad ciudadana, entre otros. Existe, además, un avance importante en la cantidad y calidad de los materiales educativos que se han producido, con el fin de trabajar con los y las estudiantes en este tema.

Incluso, en la Educación no formal, existen diversas instituciones que atienden un abanico de temas y que incluyen una concepción amplia de los derechos humanos. Además de las ONGs especializadas, se identifican otras instituciones como las Iglesias, los gremios, las asociaciones vecinales, los clubes y otras, que realizan tareas educativas en materia de educación en derechos humanos.

Algunas Instituciones y ONGs abarcan y se preocupan por una variedad de grupos de personas que, históricamente, han sufrido violaciones reiteradas y permanentes a sus derechos, como son los niños y las niñas, las mujeres, los jóvenes, los indígenas, los homosexuales y las lesbianas, los minusválidos, las personas de la tercera edad; otras se han especializado para atender sólo a algunos grupos. Algunas instituciones se especializan en la defensa y la promoción de los derechos de la mujer, de los enfermos del SIDA, del medio ambiente; del consumidor, entre otros. Es importante hacer ver que la educación no formal ha estado ligada, históricamente, a la defensa de los derechos humanos.

La educación en derechos humanos entra, necesariamente, en conflicto, en tensión con el discurso oficial porque es, en esencia, crítica, cuestionadora, problematizadora. Eso manda una relectura constante de la dinámica social en la que se desarrollan las relaciones sociales.

Es interesante hacer notar que la educación en derechos humanos se ha desarrollado a la par de otros lenguajes vinculantes, pero no iguales. A medida que la educación en derechos humanos ha ido buscando caminos, ha emergido la educación para la ciudadanía, la educación ambiental, la educación moral y cívica, la educación para la paz, la educación para la igualdad de oportunidades, la educación para la tolerancia y la no-discriminación, la educación multicultural e intercultural, la educación para la diversidad, etc. Para algunos, esta polisemia de lenguajes, esta carencia de definición clara y de límites bien definidos del campo, constituye un problema de identidad que corre el peligro de diluirse. No debería existir una competencia entre las diversas formas de aproximarse a temas tan importantes como los mencionados.

Por el contrario, deberían reforzarse y complementarse. Sin embargo, debemos reiterar que la educación en derechos humanos, apunta, por excelencia, a la transformación social, a la liberación de hombres y mujeres, al empoderamiento. Aquí radica la diferencia con otros lenguajes.

Las transformaciones que el mundo ha sufrido en las últimas décadas, han modificado el estilo de vida de las personas y las relaciones interpersonales que se establecen, tanto en el ámbito individual como en los niveles familiar, comunal, educativo, entre otros. Esa situación trae como consecuencia que las relaciones entre pueblos y culturas se hayan reorientado, y se visualicen, así, nuevos cambios en cuanto a la percepción del otro y con esta nueva visión de otredad induce a la inserción de la interculturalidad en la sociedad, y, por ende, en el sistema educativo de cada país. Esta situación afecta, directamente, el proceso pedagógico.

\section{REFERENTE HISTÓRICO SOBRE LA PEDAGOGÍA INTERCULTURAL}

La pedagogía intercultural surge en un contexto que ha evolucionado desde posturas conceptuales que buscan asimilar el tratamiento de las diferencias culturales hacia otras, abordadas con referencia en valores de democracia, de equidad y de participación social. Surge en los contextos 
europeo y americano, sobre todo, en España y Estados Unidos, considerados éstos como países de absorción de población inmigrante, la cual se ve obligada a participar, directamente, de una cultura ajena a la propia. Esta realidad se traslada al ámbito educativo como una cotidianidad, en la cual se debe dar respuesta acertada y responsable.

Aguado (2003) considera que ante esta situación, las autoridades responsables de ambos países deben priorizar, pues la atención educativa a las diferencias culturales, en la actualidad, está, ineludiblemente, asociada al incremento de la presencia de inmigrantes extranjeros en las escuelas. Las diferencias culturales han existido siempre entre la población escolar, en función de su origen social o geográfico, de su lengua, género o grupo étnico, entre otros. Sin embargo, el fenómeno migratorio ha hecho explícito lo latente, enfocando la atención en las diferencias culturales como variable educativa, y completando la diversidad como norma.

La pedagogía intercultural ha venido desarrollándose en un contexto sociopolítico determinado (caso de España y Estados Unidos), asociada a ideales de participación democrática y justicia social, en los que se considera que la multiculturalidad surgida en el ámbito norteamericano ha sido superada por la interculturalitad, al punto de que ha llegado a ser una línea de indagación y reflexión pedagógica.

En nuestro país, el tratamiento de la multiculturalidad en planteamientos de política educativa y desarrollo curricular, constituye un área que no se ha desarrollado de forma clara y consciente; de ahí que los docentes realicen prácticas interculturales sin tener claro un referente conceptual general, que vincule su accionar con el desarrollo pleno de los estudiantes.

Se han presentado en el país programas como Nuevas oportunidades, educación abierta, programas de adecuaciones curriculares, entre otros; que responden a una atención a la diversidad que no es clara, y que se refleja en los datos que arroja el Primer Informe del Estado de la Educación Costarricense (2005), el cual hace referencia, por ejemplo, a las brechas socio-espaciales existentes en los estudiantes del sistema educativo costarricense. También indica y señala que, en Costa Rica, el acceso a la educación no es homogéneo, y afirma que en nuestro país "existen importantes brechas de cobertura y resultados que se encuentran asociados a factores como la ubicación geográfica, los ingresos, el sexo y el carácter público o privado de las dependencias educativas" (Programa Estado de la Nación, p. 34).

Se atiende diversidad con una dimensión limitada, en la cual, la interculturalidad no es prioritaria. La traducción que se ha hecho del concepto de interculturalidad en nuestro país ha sido con un sentido muy restrictivo, en la medida en que se refiere a lo intercultural cuando se aplica a la presencia de grupos cultural y étnicamente diferentes, y, casi siempre, asociados a contextos económicos e históricos marginales. Éste es el caso de los nicaragüenses, los salvadoreños de las décadas de los 70s y 80s y, en la actualidad, los colombianos; situación que las autoridades educativas han tenido que asumir como su responsabilidad, al ser parte de la población estudiantil, y los docentes responsabilizarse de atender a esta población, a pesar de la falta de claridad de la política educativa.

\section{LA INTERCULTURALIDAD}

Para establecer su concepto con propiedad, es conveniente aclarar y diferenciar los términos intercultural y multiculturalidad, ya que ambos han sido utilizados como sinónimos, pero la conceptuación es diferente, de ahí que aclaramos que la pedagogía intercultural aparece en el ámbito educativo, con el fin de superar las creencias de conceptos como multiculturalismo, el cual no refleja, suficientemente, la dinámica social y las nuevas construcciones socioculturales. Por el contrario, 
la pedagogía intercultural subraya la comunicación e intercambio de formas diversas, al considerar que la diversidad es la norma en educación y que es un campo emergente en ella.

La elaboración de una teoría adecuada para referirse a la pedagogía intercultural es una tarea por realizar, y que está limitada porque los presupuestos y los fines no están definidos. La metodología específica hace referencia a la utilización de métodos diversos y los conceptos centrales no están articulados con claridad. Ante esta situación, la pedagogía intercultural hace referencia a formulaciones desde la antropología, la sociología, la psicología y la pedagogía.

La práctica educativa es considerada desde la pedagogía intercultural, en relación con las diferencias culturales de individuos y grupos, como foco de reflexión y de indagación pedagógica; propone dar respuesta a la diversidad cultural de las sociedades democráticas que respetan el pluralismo cultural.

La educación intercultural puede considerarse como un enfoque holístico e inclusivo que, partiendo del respeto y de los valores de la diversidad cultural, busca la reforma de la escuela como totalidad, para incrementar la equidad educativa, superar el racismo, la discriminación y la exclusión, favorecer la comunicación y la competencia intercultural, y apoyar el cambio social, según los principios de justicia social y de derechos humanos.

Dentro de la pedagogía intercultural se define a la escuela intercultural, como aquella que asume los objetivos propuestos y responde al reto de educar a diferentes grupos, haciendo la escolaridad igual y equiparable para todos, atendiendo las diferentes características existentes entre los alumnos y las alumnas. Se busca potenciar una escuela no sólo de ganadores o perdedores, sino una escuela cuyo propósito sea aprender la capacidad de aprender; esto conlleva a un cambio de formas de pensar e interactuar de todos y admitir que los estudiantes aprenden de múltiples formas, y que sus capacidades no son algo estático, sin olvidar, por supuesto, las limitaciones personales. "De ahí que las estrategias y actividades deben estar en consonancia con el análisis, necesidades y previsión de objetivos propuestos en la planificación de la enseñanza, con orientaciones que promuevan contrarrestar el racismo, la discrimación; fomentando el aprendizaje cooperativo" (Aguado, 2003, p. 122).

Ahora bien, según Sabariego (2002), se puede entender interculturalidad como un concepto o idea en el cual:

[...] ante el nuevo horizonte de globalización e interdependencia que hace urgente un nuevo orden internacional basado en la "cooperación y solidaridad", la educación intercultural incorpora la idea del compromiso como ciudadanos en la construcción de una sociedad humanamente global, con pleno sentido si se plantea desde un paradigma basado en la alteridad, el diálogo y una apuesta sin tapujos por alguna forma de universalismo. (p. 92)

Interculturalidad es, de acuerdo con la Coordinación Educativa y Cultural Centroamericana (CECC) (2002), “[...] la promoción sistemática y gradual, desde el Estado y desde la sociedad civil, de espacios de interacción positiva que vayan abriendo y generalizando relaciones de confianza e intercambio, regulación pacífica del conflicto, cooperación y convivencia" (p. 52).

Si se hace un análisis de ambas definiciones, la interculturalidad, así planteada, constituye la búsqueda de las relaciones culturales que eliminen la subordinación de una cultura ante otra; y, además, nos acerca a una educación intercultural que, primero, trata de un enfoque educativo, una manera de entender la educación y supone un proceso continuo (y no un programa acción puntual). Este planteamiento de enfoque holístico, afecta a todas las dimensiones educativas y no sólo al currículo, un enfoque inclusivo, que supone educación de y para todos, y no sólo de minorías o inmigrantes. 
La interculturalidad percibe la diversidad como un valor y no como una deficiencia y pretende reformar la escuela para conseguir una educación de calidad para todos y todas, en la cual los objetivos generales fundamentales son: equidad, antirracismo, competencia intercultural y transformación social.

Las teorías multiculturalistas presuponen la validez de las culturas de las minorías por parte de las instituciones educativas y de la sociedad global. Ante esta situación, se determinan dos posibilidades para la aceptación y la validación de las culturas: por un lado, es aceptar la diversidad, incluyéndola en actividades escolares específicas y abriendo los programas a los logros de las otras culturas en los campos artísticos, científicos y organizativos; y, por otro, es procurar desarrollar escalas de valores abiertos, en las que se aprecie la diferencia como un elemento positivo para cada una de las culturas en contacto.

El pluralismo cultural implica repensar la propia sociedad de acogida y extender esta concepción a todos los niveles de la enseñanza y a todas las escuelas, no solamente a las que tienen niños(as) de grupos minoritarios. En aquellos países en los que la multiculturalidad es más antigua (como en el Reino Unido), se abandonó la idea de una integración automática de los(as) inmigrantes en la sociedad, hasta que se evidenció el fracaso escolar, por lo cual se plantearon programas multiculturales que incluían aspectos de la cultura inmigrante, con el fin de desarrollar estrategias pedagógicas específicas.

El fenómeno de la universalización-particularismo y la homogenización-diferenciación está constituido por dos tendencias antagónicas que se debaten, dialécticamente, en esta sociedad multicultural y multiétnica. La tendencia a la internacionalización o universalización de la cultura de los valores y de la producción, que, en ciertos aspectos, puede derivar la globalización, homogenización o uniformización de la vida cotidiana, frente a la tendencia al particularismo y a la reivindicación de las particularidades de grupo, etnia o nación. Para Merino y Muñoz (1998, s. p.), "la 'aldea global' de McLuhan se responde con la "nostalgia de la tribu"'.

Este antagonismo dialéctico no siempre concluye en una síntesis integradora. Por el contrario, en ocasiones, provoca y potencia conflictos constantes en las relaciones interindividuales, interpoblacionales o interétnicas, incrementando, progresivamente, actitudes intolerantes, marginación, racismo y cualquier otro tipo de manifestación de intolerancia.

Las migraciones, como fenómeno permanente, tanto por su fuerza cuantitativa como por su complejidad cualitativa, cuestionan el modelo tradicional de sociedad y fuerzan la reflexión, la gestión y la acción de los grupos culturales y étnicos o de otra procedencia, en la organización de estas sociedades y en el concepto, la construcción y la constitución de la sociedad futura.

La existencia de todo un movimiento pedagógico dirigido a responder no sólo al reto que significa la realidad de una sociedad multicultural y étnicamente plural, sino, también, a implicarse en el proyecto de sociedad futura, ya emergente, que significa esta realidad plural y compleja, caracterizada por el intercambio y la movilidad de las personas y de los sistemas de valores y modelos culturales y sociales, así como por la convivencia en un mismo lugar de idéntica pluralidad cultural y étnica, es base, desarrollo y meta de la pedagogía intercultural.

El estado actual de la respuesta de la pedagogía a este problema multicultural y multiétnico, ¿permite hablar de pedagogía intercultural al igual que de pedagogía cognitiva, social, etc., o, simplemente, de una práctica educativa constituida por actividades y programas específicos sugeridos para resolver problemas puntuales y transitorios, pero sin constituir, en sí mismos, un nuevo modelo teórico científico?

Éste es el reto principal al que ha de enfrentarse la pedagogía intercultural. Se dice pedagogía intercultural y no educación intercultural, porque la amplitud y la complejidad del problema superan los límites de la práctica educativa para convertirse en un auténtico problema pedagógico. 
El estado actual de la realidad educativa presenta una doble vertiente. La primera se caracteriza por actividades y programas concretos de tipo funcional que los profesores, en contacto directo con la situación en sus aulas, se han visto obligados, en unos casos, a improvisar, y, en otros, a construir y a desarrollar con una más amplia planificación, ante el hecho perturbador de la presencia, de los alumnos inmigrantes o de otras etnias minoritarias en sus aulas. La segunda vertiente recoge el cauce teórico-práctico que se fundamenta en el análisis y los estudios sobre la sociedad multicultural y multiétnica y, en concreto, sobre el fenómeno de las migraciones en esta realidad social, considerada el tema como un problema global y complejo, que supera la simple respuesta funcional y puntual a una necesidad local. La investigación básica y aplicada para ofrecer modelos de análisis y de actuación, con sus consecuentes ayudas instrumentales, configuran esta segunda vertiente.

\section{DE LA EDUCACIÓN MULTICULTURAL A LA PEDAGOGÍA INTERCULTURAL}

Una sociedad multicultural es aquella que se caracteriza por la pluralidad de los aportes de otras culturas o civilizaciones a la cultura de origen. A pesar de que el concepto de multicultural nos ayuda plantear las relaciones en el seno de la sociedad, también nos demuestra que este término está inmerso en el ámbito educativo, y, por tanto, implica reflexión sobre el desarrollo de la autoconciencia de la cultura, aceptación del potencial conflicto de cultura, deseo de aprender sobre la propia realidad cultural y la de los otros, incremento y mejora de la comunicación entre las personas y el reconocimiento de la universalidad de la multiculturalidad.

La educación multicultural, según Bagkey y Verna (citados por Aguado, 2003) es:

[...] un sistema de educación que, en una sociedad étnicamente compleja, intenta responder a las necesidades de autoconcepto, cognitivas y culturales de los grupos e individuos procedentes de diversas culturas. Promueve la igualdad de resultados escolares entre grupos e individuos, tolerancia y respeto entre los grupos y, finalmente, igualdad de status, recursos, acceso, y poder entre los diferentes grupos étnicos/ culturales de la sociedad. (p. 6)

La educación multicultural pretende cultivar actitudes positivas respecto a la diversidad cultural presente en una sociedad, estas actitudes positivas han de responder a una comunicación asertiva, tanto verbal como no verbal, en la cual se fomenta la capacidad de reflexión, resocialización, comprensión y enriquecimiento mutuo entre culturas.

La pedagogía intercultural es más amplia y compleja, pues analiza la práctica educativa considerando la multiculturalidad. Aguado (2003) define la pedagogía intercultural como:

La reflexión sobre la educación, entendida como elaboración cultural, y basada en la valoración de la diversidad cultural. Promueve prácticas educativas dirigidas a todos y cada uno de los miembros de la sociedad en su conjunto. Propone un modelo de análisis y de actuación que afecte a todas las dimensiones del proceso educativo. Se trata de lograr la igualdad de oportunidades (entendida como oportunidades de elección y de acceso a recursos sociales, económicos y educativos), la superación del racismo y la adquisición de competencias interculturales en todas las personas, sea cual sea su grupo cultural de referencia. (p. 63) 
La diversidad a la que hace referencia el concepto de pedagogía intercultural es una visión holística e integral de ella: la idea de diversidad en un espacio intercultural busca la unidad.

El respeto a la diversidad cultural y a la convivencia intercultural, es una posibilidad, meta, ideal, de convivencia armónica entre las sociedades y va más allá de los límites establecidos por razas, grupos étnicos o nacionales, y en interacción con diversos significados y contextos educativos.

Por tanto, la educación ha de orientarse hacia el fomento de la interdependencia y la cooperación entre los pueblos para favorecer la universalidad, el reconocimiento recíproco de las culturas y una síntesis sociocultural nueva. Dicho de otra manera: es preciso promover la idea de la diversidad cultural, la igual validez de todas las culturas, el interés por otras culturas como fuente de enriquecimiento personal y social.

El respeto a la diversidad cultural y su fomento es un proyecto pedagógico, cuyo último propósito es la plena integración social de las minorías étnicas y la eliminación de toda fuente de discriminación; en el que los objetivos están orientados a lograr una reforma de la educación, cambios no sólo en el currículo, sino en la formación docente y en todas las dimensiones de los procesos de enseñanza y de aprendizaje, garantizar la inclusión e integración y la superación de cualquier manifestación de racismo, discriminación o actitud xenófoba del docente y el discente.

\section{ENFOQUES Y MODELOS DE EDUCACIÓN MULTICULTURAL}

Para que el concepto de interculturalidad pueda tener la connotación integral que se le ha asignado, ha tenido que evolucionar y sufrir transformaciones, para amalgamar la diversidad como algo positivo y enriquecedor en la vida de todas las personas y de la sociedad.

Sabariego (2002) nos aclara los enfoques y modelos de la educación multicultural (véase la Tabla $\mathrm{N}^{\mathrm{o}}$ 1).

Los datos de la tabla reflejan el cambio que se ha venido dando en la atención a la interculturalidad; nótese que los proyectos educativos están dirigidos hacia lo global, hacia la formación de ciudadanos activos, críticos, solidarios y democráticos en un mundo plural.

Por tanto, según Aguado (2003) dentro de un enfoque global, la pedagogía intercultural considera, dentro de su definición y objetivos, que:

- $\quad$ Las diferencias culturales se sitúan en el foco de la reflexión en educación.

- Las diferencias son la norma, no están asociadas a deficiencias o déficits respecto a un supuesto patrón ideal.

- $\quad$ Las diferencias culturales son dinámicas y cambiantes, adaptativas.

- La diversidad cultural se refiere a las diferencias en los significados que generamos, que compartimos en un determinado grupo.

- $\quad$ Se dirige a todos los miembros y sectores de la sociedad.

- $\quad$ Se propone el logro de la igualdad de oportunidades educativas de todos los grupos socioculturales.

- Se orienta a desarrollar competencias interculturales en todos los estudiantes y profesores.

- Un objetivo básico es la superación del racismo y la discriminación, como hecho individual e institucional. (p. 65) 


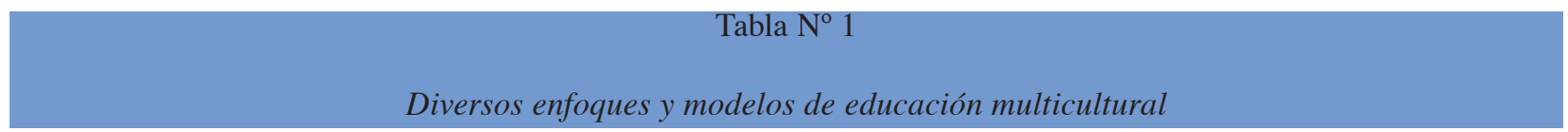

\begin{tabular}{|c|c|}
\hline Enfoques & Modelos educativos \\
\hline \multirow{3}{*}{$\begin{array}{l}\text { Hacia la afirmación } \\
\text { hegemónica de la cultu- } \\
\text { ra del país de acogida. }\end{array}$} & $\begin{array}{l}\text { Asimilacionista. El alumnado de minorías étnicas se incorpora al sistema escolar normal } \\
\text { que no contempla las peculiaridades de su identidad cultural de origen. }\end{array}$ \\
\hline & $\begin{array}{l}\text { Compensatorio. Las diferencias culturales se consideran un déficit que no permite a quien } \\
\text { lo tiene alcanzar el éxito escolar. Se ve necesaria una recuperación con programas de } \\
\text { educación compensatoria. }\end{array}$ \\
\hline & $\begin{array}{l}\text { Segregacionista. En una sociedad claramente fragmentada se relega a las minorías étnicas } \\
\text { en escuelas especiales, impidiendo o dificultando su acceso al sistema educativo de la } \\
\text { cultura dominante. }\end{array}$ \\
\hline \multirow{2}{*}{$\begin{array}{l}\text { Hacia el reconocimiento } \\
\text { de la pluralidad de cul- } \\
\text { turas en aspectos par- } \\
\text { ciales o globales dentro } \\
\text { del marco escolar }\end{array}$} & $\begin{array}{l}\text { Currículo multicultural. Modificación parcial o total del currículo escolar para la intro- } \\
\text { ducción de contenidos multiculturales. }\end{array}$ \\
\hline & $\begin{array}{l}\text { Pluralismo cultural. Reconocimiento del derecho a la expresión propia de la identidad } \\
\text { cultural de las minorías étnicas en la escuela. Se propone la separación parcial o total del } \\
\text { grupo en instrucción educativa a la posibilidad de tener un currículo diferenciado. }\end{array}$ \\
\hline \multirow{3}{*}{$\begin{array}{l}\text { Hacia una opción inter- } \\
\text { cultural basada en la } \\
\text { simetría cultural }\end{array}$} & $\begin{array}{l}\text { La orientación multicultural. Se vincula la orientación personal al desarrollo de la iden- } \\
\text { tidad cultural. }\end{array}$ \\
\hline & $\begin{array}{l}\text { Educación no-racista. Debe procurarse evitar la transmisión de valores y conductas racis- } \\
\text { tas. No se cuestiona la dimensión ideológica. }\end{array}$ \\
\hline & $\begin{array}{l}\text { Intercultural (o diferencia cultural). Respeta la diversidad cultural y promueve la comuni- } \\
\text { cación y el diálogo entre grupos culturales diversos. Es para todo el alumnado. Prioridad } \\
\text { a la solidaridad y reciprocidad entre culturas. }\end{array}$ \\
\hline \multirow{3}{*}{$\begin{array}{l}\text { Hacia una sociedad más } \\
\text { justa, luchando contra } \\
\text { la asimetría cultural, } \\
\text { social y política. (enfo- } \\
\text { que sociocrítico) }\end{array}$} & $\begin{array}{l}\text { Holístico de Banks. Aborda la educación intercultural en la escuela desde un enfoque } \\
\text { institucional. Incorpora elementos de denuncia y lucha contra la discriminación y el } \\
\text { racismo. }\end{array}$ \\
\hline & Antirracista. Denuncia las raíces estructurales del racismo. \\
\hline & $\begin{array}{l}\text { Radical. Acción de sensibilización realizada en el interior de las minorías culturales mar- } \\
\text { ginadas. Vincula procesos educativos, organizativos y políticos. }\end{array}$ \\
\hline $\begin{array}{l}\text { Enfoque global: incluye } \\
\text { la opción intercultural } \\
\text { y la lucha contra toda } \\
\text { discriminación }\end{array}$ & $\begin{array}{l}\text { Proyecto educativo global. Intenta valorar la diversidad y promover la igualdad. Educar } \\
\text { para la ciudadanía en una sociedad multicultural. }\end{array}$ \\
\hline
\end{tabular}

Nota. Tomado de Sabariego, 2002.

Se puede considerar que la pedagogía intercultural no sólo busca la igualdad y la eliminación de cualquier forma de discriminación, sino que busca crear competencias interculturales en los seres humanos; pretende abrir espacios reales para la igualdad de condiciones entre todos los educandos, fomenta y lucha por el respeto de los derechos humanos. Además, se contribuye a la cohesión social, a una cultura de paz, y, sobre todo, garantiza la educación para una vida digna y de calidad para todos y todas.

Estos criterios de igualdad plantean una lucha constante de reforma en el sistema educativo, un movimiento social, no un simple cambio bajo la consigna de "vivir y dejar vivir el pluralismo", sino un movimiento que integre, efectivamente, a todos los discentes, afirmando 
la diversidad como una forma de vida y proceso de desarrollo en el cual, el proyecto de escuela intercultural sea veraz y contextualice en la realidad de cada pueblo. La escuela, como sistema social, ha de responder a la interculturalidad en diversas variables como la participación de la comunidad, el lenguaje, los estilos de aprendizaje, la cultura escolar y el currículo, la didáctica, los materiales de aprendizaje, la política educativa, entre otros. La dimensión de la educación intercultural es muy grande y compleja, y abarca la integración de contenidos, los procesos de construcción del conocimiento, la reducción del prejuicio, una pedagogía de la equidad y crítica, y un empoderamiento de una cultura escolar favorable a la diversidad (Sabariego, 2002).

\section{LA ESCUELA INTERCULTURAL}

El medio escolar intercultural es aquel que asume, como propios, los objetivos de la educación intercultural y responde al reto de educar a diferentes grupos culturales o étnicos, planteando la educación igual para todos y todas, y atendiendo, además, la diversidad de características personales en cada estudiante.

La Coordinación Educativa y Cultural Centroamericana (CECC) (2002) afirma que a la escuela se le presenta un gran reto, por "[...] ser un laboratorio para la adquisición y la práctica de conocimientos, actitudes y procedimientos útiles, para resolver los grandes problemas, y atender los diversos fenómenos sociales del mundo de hoy" (p. 64).

Asimismo, la CECC considera que la escuela es el lugar ideal para construir espacios de interculturalidad y, sobre todo, formación en cuanto a competencias para la atención y la convivencia intercultural; además, afirma que es un espacio oportuno para realizar investigaciones sobre las relaciones interétnicas en la comunidad y en el país, para el desarrollo de conocimientos sobre la riqueza cultural y lingüística de su contexto inmediato-mediato; es un espacio para el reconocimiento de diferentes formas de relación con diversas culturas y, por tanto, una forma de erradicar ideas racistas o xenófobas sobre otras culturas, y es, también, el lugar adecuado para ejecutar actitudes y valores que faciliten la convivencia humana entre personas con identidades étnico-culturales diversas.

En relación con esta idea, Delors, Al Mufti, Amagi, Carneiro, Chung, Geremek et al. (1996) identifican en la educación, al menos, tres dimensiones que apuntan al desarrollo integral de las nuevas generaciones: la dimensión ética y cultural, la ciencia y la tecnología, y la economía y el ámbito social. Delors et al. dejan claro que la educación debe integrar la atención a la diversidad cultural desde un marco ético, que respete al ser humano en su integralidad y que se fomenten los derechos humanos.

La Declaración Mundial de la Diversidad Cultural de la UNESCO (2 de noviembre, 2001), en su artículo 3, dicta: "La diversidad cultural amplía las posibilidades de elección que se brindan a todos; es una de las fuentes del desarrollo, entendido no solamente en términos de crecimiento económico, sino también como medio de acceso a una existencia intelectual, afectiva, moral y espiritual satisfactoria".

De ahí que la escuela es la llamada a la formación de estas competencias, a revalorar los aspectos culturales de la educación y a darles una nueva visión y función, con el fin de que la meta final de la educación intercultural sea transformar la sociedad en un medio más justo y democrático. Se trata, sin duda, de una meta ambiciosa que confía en las escuelas como agentes de cambio social y educativo. 
Las instituciones educativas se encuentran en una posición privilegiada para promover la transformación social, de modo que se superen las desigualdades (racismo personal e institucional, etnocentrismo, desigual distribución de recursos, relaciones de poder desiguales, etc.).

Según Aguado (2003), el medio escolar intercultural, basado en el paradigma holístico multifactorial, debe contemplar varios factores, tales como:

- $\quad$ El personal de la escuela mantiene actitudes y valores democráticos e inclusivos.

- La escuela tiene normas que reflejan y legitiman la diversidad étnica y cultural.

- Los procedimientos de diagnóstico y evaluación favorecen la igualdad de oportunidades/ resultados.

- $\quad$ El currículo y los materiales de enseñaza presentan las diversas perspectivas culturales sobre conceptos, resultados y problemas.

- El pluralismo lingüístico y la diversidad son valorados y promovidos.

- $\quad$ Los estilos de enseñanza son utilizados según los grupos culturales.

- Los estudiantes de diferentes grupos culturales disfrutan del mismo estatus en la escuela.

- Los profesores y estudiantes adquieren las habilidades y perspectivas necesarias para reconocer formas variadas de racismo y emprender acciones orientadas a su eliminación. (p. 104)

Estos factores son el reflejo claro de la importancia de las competencias interculturales que debe poseer el docente para el desarrollo de un clima de centro educativo inclusivo, y de apertura al cambio.

\section{COMPETENCIAS INTERCULTURALES EN LOS DOCENTES}

La formación docente en competencias interculturales es fundamental, esta formación debe darse con un enfoque más crítico, cuya perspectiva asume al profesor como profesional reflexivo capaz de analizar los mecanismos de control social del conocimiento, el poder de las estructuras y las instituciones sociales, y, sobre todo, capaz de desarrollar destrezas para la acción social.

La diversidad y la educación intercultural se han de convertir en tópicos de constante conversación entre docentes. El Informe Mundial sobre Educación de la ONU (1998) hace hincapié en la necesidad de la constante formación docente y considera que: "se está generalizando la opinión de que la docencia, de la misma manera que otras profesiones, es una actividad de aprendizaje, y que las personas que la ejercen deben tener oportunidades de actualizar y renovar sus conocimientos, aptitudes y capacidades periódicamente a lo largo de su carrera" (p. 69).

La formación de competencias interculturales se debe convertir en el nuevo reto de los docentes, una formación sólida que trascienda en la práctica pedagógica y en la dinámica y formación de los discentes.

\section{COMPETENCIAS INTERCULTURALES}

Las competencias interculturales se consideran como las habilidades cognitivas, afectivas y prácticas para desenvolverse, eficazmente, en un medio intercultural de ahí que Aguado (2003) opine que: "están orientadas a crear un clima educativo donde las personas se sientan aceptadas y apoyadas por sus propias habilidades y aportaciones, así como permitir la interacción efectiva y 
justa entre los miembros del grupo. El desarrollo de estas competencias es un objetivo básico de toda iniciativa pedagógica intercultural" (p. 141).

Para esta autora, las competencias interculturales se caracterizan por:

- $\quad$ El educador como facilitador y potenciador más que como controlador recurriendo a técnicas de control indirecto y proporcionando variedades, oportunidades para que los educandos determinen sus actividades de aprendizaje.

- Utilizar centros de interés, proyectos de grupo, programas individualizados y actividades que permitan a los estudiantes escoger el momento en que comienzan y terminan las tareas.

- $\quad$ Atender a las necesidades e intereses de cada persona y verle como un individuo, antes que como miembro de un determinado grupo cultural.

- $\quad$ Promover situaciones sociales diversas -formales e informales, estructuradas y abiertas-para favorecer los contactos y el conocimiento mutuo.

- Utilizar fórmulas diversas de motivación para aprender y actuar según una variedad de razones o de sentimientos. Proporcionar refuerzos de diverso tipo -verbal/no verbal, mediato/ inmediato-.

- Atender a los preliminares y a las fórmulas sociales características de cada grupo cultural, al comenzar y al concluir una actividad. Enseñar diferencias en el trato, cortesía y conducta habitual de los diferentes grupos.

- $\quad$ Proporcionar oportunidades adicionales a los grupos minoritarios para formar parte de comités, proyectos cooperativos y, también, actividades individuales que fomenten autoimagen positiva.

- Utilizar diferentes estilos de enseñanza según los estilos de aprendizaje de los estudiantes al organizar el trabajo y el ocio.

- Facilitar el proceso de adquisición de competencias multiculturales simulaciones, discusiones, centros de interés, comunicación intercultural.

- Facilitar la adaptación a la escuela, previendo posibles dificultades, compensando de déficit en habilidades básicas, estableciendo fórmulas de acogida a los recién llegados.

- Observar y practicar diferentes estilos comunicativos. Recurrir a la ayuda de voluntarios de las comunidades de referencia de las comunidades participantes.

- Diseñar actividades que estimulen el desarrollo cognitivo y perceptivo -tarea de descubrimiento, indagación conformación de hipótesis, tareas piagetianas-. (p. 138)

Además, Sabariego (2002) expone sobre competencias interculturales que:

- $\quad$ La integración del contenido hace referencia al grado en que el profesorado utiliza ejemplos y contenidos procedentes de varias culturas en su modelo educativo.

- $\quad$ El proceso de construcción del conocimiento hace referencia a que el profesor debe ayudar al alumno a entender cómo los marcos de referencia, perspectiva y sesgos implícitos en una disciplina influye en la forma de construcción del conocimiento.

- La reducción del prejuicio está centrado en las características de las actitudes raciales del alumnado y en la forma como pueden modificarse por medio de diferentes métodos y recursos.

- Una pedagogía de la equidad existe cuando el profesorado modifica su forma de enseñar, de manera que facilita el éxito académico de todo el alumnado.

- Una cultura escolar favorable al empoderamiento que busca desarrollar las destrezas para superar las injusticias y las desigualdades sociales. (p. 101) 
Las actitudes son la base de las competencias interculturales, éstas se pueden traducir en cualidades como la apertura para considerar válidas otras culturas al igual que la propia. Esto implica poseer conocimiento acerca de los grupos sociales, sus tradiciones y costumbres, el papel de los derechos humanos en la determinación de una serie de competencias, no sólo el conocimiento de la cultura, sino de cómo funciona y cómo actúa, en relación con las relaciones interpersonales y la identidad, entre otros.

Otra habilidad o destreza relacionada con las competencias interculturales, es la capacidad de interpretación y comparación, desde diversas perspectivas, hechos, ideas, documentos, etc.; y la capacidad de aprendizaje e interacción, desde una actitud para aprender nuevos conocimientos y ponerlos en práctica en situaciones de interacción y comunicación.

El desarrollo de competencias interculturales no sólo debe considerarse como algo propio a la formación docente, sino que ha de contemplarse como un objetivo de todo el programa de educación y formación en la práctica educativa; es una toma de conciencia constante y, por ende, permeable en las prácticas educativas, en la organización del centro.

No se trata de incorporar elementos de reflexión y sensibilización de forma aislada, sino de impregnar en el currículo y la práctica pedagógica con experiencias que permitan el desarrollo de competencias interculturales, con el fin de transversalizar los derechos humanos en las prácticas educativas cotidianas. Para poder alcanzar estas destrezas deseables en todos los docentes, Aguado (2003) cita a Pedersen (1994) e identifica tres elementos básicos por desarrollar: "[...] la autoconciencia, los conocimientos y las habilidades o destrezas" (p.143). Estos elementos básicos invitan a una constante reflexión de la práctica pedagógica docente, la autovaloración de las propias competencias interculturales y de la forma de relacionarse con las otras culturas, la búsqueda de información para erradicar mitos y estereotipos sobre otras culturas y la propia, potencian habilidades y destrezas interculturales.

\section{REFERENCIAS BIBLIOGRÁFICAS}

Aguado, T. (2003). Pedagogía intercultural. Madrid, España: McGraw-Hill.

Coordinación Educativa y Cultural Centroamericana (CECC). (2002). La práctica de la Interculturalidad en el aula. San José, Costa Rica: Autor.

Delors, J. (Coord.). Al Mufti, I., Amagi, I., Carneiro, R., Chung, F., Geremek, B., et al. (1996). La educación encierra un tesoro. (Informe a la UNESCO de la Comisión Internacional sobre la educación para el siglo XXI). Madrid, España: Santillana Ediciones UNESCO.

Ianni, O. (1995). Metáforas de la globalización. Revista de Ciencias Sociales, $N^{o} 2$, s. pp.

Jimeno Sacristán, J. (2005). La educación aún es posible. Madrid, España: Editorial Morata.

Martínez, A. \& Sáenz, J. (1998). Del Racismo a la Interculturalidad. Competencias de la educación. Madrid,España: Narcea.

Merino, J. \& Muñoz, A. (mayo-agosto, 1998). Ejes de debate y propuestas de acción para una pedagogía intercultural [versión electrónica]. Revista Iberoamericana de Educación, Nº 17, s. p. 
Organización de las Naciones Unidas para la Educación. (1998). Informe mundial sobre la educación. Los docentes y la enseñanza en un mundo en mutación. [on line]. Madrid, España: UNESCO.

Proyecto Estado de la Nación en desarrollo humano sostenible. (2005). Primer Informe Estado de la Educación Costarricense. San José, Costa Rica: Autor

Sabariego, M. (2002). La educación Intercultural. Ante los retos del siglo XXI. Vizcaya, España: Editorial Desclée de Brouwer.

UNESCO. (2 de Nov., 2001). Declaración Mundial de la Diversidad cultural. Recuperado el 25 de setiembre de 2007, de http://portal.unesco.org/es/ev.php-URL_ID=13179\&URL_DO=DO_ TOPIC\&URL_SECTION=201.html

\section{OTRAS FUENTES CONSULTADAS}

Besalú, X. (2002). Diversidad cultural y educación. Madrid: Síntesis.

Booth, T. \& Ainscow, M. (2000). Índice de Inclusión. Desarrollando el aprendizaje y la participación en las escuelas. Santiago, Chile: OREALC/UNESCO.

Gabino, J. (2002). Educar y convivir en la cultura global. Madrid, España: Ediciones Morata.

Jordán, J. A. (1994). La escuela multicultural. Un reto para el profesorado. Barcelona, España: Paidós.

Meléndez, M. (2002). Educación para la Diversidad en una sociedad de conocimiento. Manizales, Colombia: Universidad de Manizales.

Meléndez, M. (2002). Diversidad y equidad: paradigma educativo emergente para la Costa Rica en vías de Desarrollo. Revista Parlamentaria. Vol. 12, N², 81-96.

Us, P. (2002). La práctica de la Interculturalidad en el aula. San José, Costa Rica: CECC. 